\title{
Investigation of the formaldehyde differential absorption cross section at high and low spectral resolution in the simulation chamber SAPHIR
}

\author{
T. Brauers ${ }^{1}$, J. Bossmeyer ${ }^{1, *}$, H.-P. Dorn ${ }^{1}$, E. Schlosser ${ }^{1}$, R. Tillmann ${ }^{1}$, R. Wegener ${ }^{1}$, and A. Wahner ${ }^{1}$ \\ ${ }^{1}$ Institut für Chemie und Dynamik der Geosphäre (ICG-II: Troposphäre), Forschungszentrum Jülich, Germany \\ *now at: Cohausz \& Florack, Düsseldorf, Germany
}

Received: 12 January 2007 - Published in Atmos. Chem. Phys. Discuss.: 26 February 2007

Revised: 11 June 2007 - Accepted: 3 July 2007 - Published: 9 July 2007

\begin{abstract}
The results from a simulation chamber study on the formaldehyde (HCHO) absorption cross section in the UV spectral region are presented. We performed 4 experiments at ambient $\mathrm{HCHO}$ concentrations with simultaneous measurements of two DOAS instruments in the atmosphere simulation chamber SAPHIR in Jülich. The two instruments differ in their spectral resolution, one working at $0.2 \mathrm{~nm}$ (broad-band, BB-DOAS), the other at $2.7 \mathrm{pm}$ (high-resolution, HR-DOAS). Both instruments use dedicated multi reflection cells to achieve long light path lengths of $960 \mathrm{~m}$ and $2240 \mathrm{~m}$, respectively, inside the chamber. During two experiments $\mathrm{HCHO}$ was injected into the clean chamber by thermolysis of well defined amounts of paraformaldehyde reaching mixing rations of $30 \mathrm{ppbV}$ at maximum. The HCHO concentration calculated from the injection and the chamber volume agrees with the BB-DOAS measured value when the absorption cross section of Meller and Moortgat (2000) and the temperature coefficient of Cantrell (1990) were used for data evaluation. In two further experiments we produced HCHO in-situ from the ozone + ethene reaction which was intended to provide an independent way of $\mathrm{HCHO}$ calibration through the measurements of ozone and ethene. However, we found an unexpected deviation from the current understanding of the ozone + ethene reaction when $\mathrm{CO}$ was added to suppress possible oxidation of ethene by $\mathrm{OH}$ radicals. The reaction of the Criegee intermediate with $\mathrm{CO}$ could be 240 times slower than currently assumed. Based on the BB-DOAS measurements we could deduce a high-resolution cross section for $\mathrm{HCHO}$ which was not measured directly so far.
\end{abstract}

Correspondence to: T. Brauers

(th.brauers@fz-juelich.de)

\section{Introduction}

Differential Optical Absorption Spectroscopy (DOAS) is widely used in atmospheric research to measure the concentration of trace gases by their absorption in the visible and near UV spectral regions. The review of Platt (2000) provides an overview on the technique and possible applications. The trace gases which can be measured by DOAS range from radicals like $\mathrm{OH}, \mathrm{BrO}$, and $\mathrm{NO}_{3}$ to small molecules like $\mathrm{NO}_{2}$, $\mathrm{SO}_{2}$, and $\mathrm{HCHO}$ to larger molecules like toluene and benzaldehyde. DOAS applications split into passive DOAS instruments which use scattered sun light (cf. MAX-DOAS) and active DOAS instruments having a distinct light source (lamps or lasers). The latter have been used in open long path and folded path setups. Multiple reflection cells, however, allow the setup of DOAS measurements with long light paths inside simulation chambers of different sizes (e.g. De Haan et al., 1999; Kleffmann et al., 2006; Schlosser et al., 2006; Bossmeyer, 2006).

In this study we focus on DOAS measurements of formaldehyde, HCHO. It is a key compound in the tropospheric photo-chemistry (e.g. Carlier et al., 1986; FinlaysonPitts and Pitts, 2000). HCHO exhibits a strong electronic transition from the ground state to the first excited singlet state $(260-360 \mathrm{~nm}), S_{1} \longleftarrow S_{0}$, giving rise to the $\tilde{\mathrm{A}}^{1} \mathrm{~A}_{2}-\tilde{\mathrm{X}}^{1} \mathrm{~A}_{1}$ band system, which consists of an extended progression of vibronic bands. The formaldehyde absorption spectrum in the near UV between $300 \mathrm{~nm}$ and $350 \mathrm{~nm}$ (Fig. 1) was measured many times at different spectral resolutions (Bass et al., 1980; Cantrell, 1990; Rogers, 1990; Meller and Moortgat, 2000; Bogumil et al., 2003; Pope et al., 2005; Smith et al., 2006; Gratien et al, 2007). A recent analysis of the differences in the HCHO spectra by Hak et al. (2005) referenced all spectra to the Meller and Moortgat

Published by Copernicus Publications on behalf of the European Geosciences Union. 


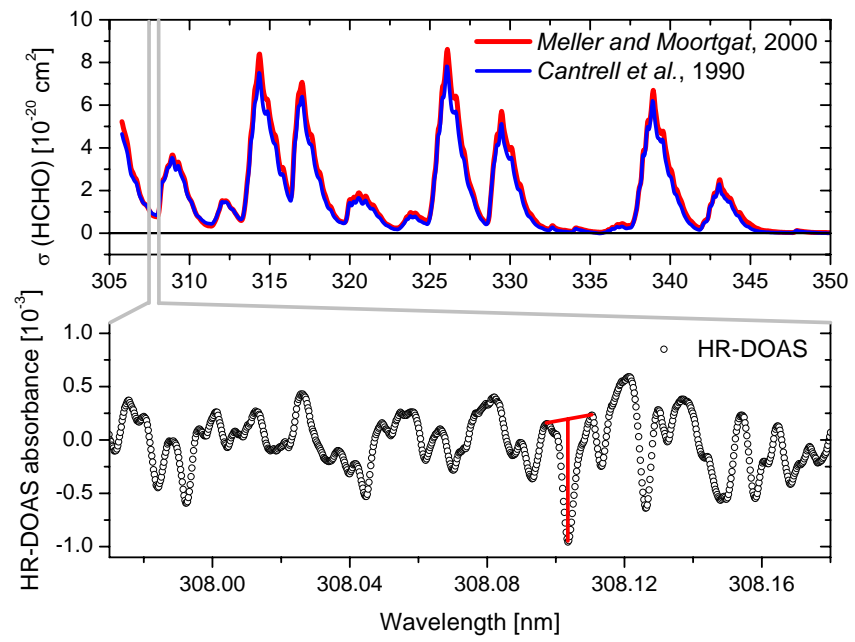

Fig. 1. Upper panel: HCHO cross sections (Meller and Moortgat, 2000; Cantrell, 1990) convolved to a resolution of $0.2 \mathrm{~nm}$ and interpolated to a wavelength grid of $0.04 \mathrm{~nm}$. Lower panel: $\mathrm{HCHO}$ absorbance measured by the HR-DOAS at a resolution of $2.7 \mathrm{pm}$ in the narrow range extending over $0.21 \mathrm{~nm}$. The differential optical density of the absorption line used to scale the data is marked in red.

(2000) data which are recommended by IUPAC (Atkinson et al., 2006) and NASA (Sander et al., 2006). Hak et al. used a spectral resolution of a broad-band DOAS instrument of $0.5 \mathrm{~nm}$. The integrated band intensities of the most recent cross section measurements of Smith et al. (2006) is (depending on the vibrational band) between $0.1 \%$ and $14 \%$ higher than the measurements of Meller and Moortgat (2000) while older data tend to be lower; i.e. the previous recommendation of NASA based on Cantrell (1990) is 11\% lower than the Meller and Moortgat (2000) data.

The spectral resolution of the original HCHO absorption cross sections published range from $3.5 \mathrm{pm}$ (Smith et al., 2006) to $0.11 \mathrm{~nm}$ (Bogumil et al., 2003). An effective cross section for broad-band-DOAS can be calculated using any of these cross sections by convolution with an appropriate instrument function. For the high-resolution DOAS (HRDOAS) instrument designed to detect tropospheric $\mathrm{OH}$ radicals (Hausmann et al., 1997; Brauers et al., 2001; Schlosser et al., 2006) no literature data at sufficiently high spectral resolution $(2.7 \mathrm{pm})$ is available. However, a comparison between the highest resolution literature data of Smith et al. (2006) and the HR-DOAS data is given in the discussion of this paper .

This article presents measurements of $\mathrm{HCHO}$ with two DOAS instruments at different spectral resolutions $(0.2 \mathrm{~nm}$ and $2.7 \mathrm{pm}$ ) which were performed at the atmosphere simulation chamber SAPHIR. HCHO mixing ratios were in the lower ppbV range in contrast to the laboratory measurements where mixing ratios in the percent range are applied.
Therefore any recombination or polymerisation of $\mathrm{HCHO}$ vapour can be excluded in this study. In one set of experiments $\mathrm{HCHO}$ was injected by means of thermolysis of paraformaldehyde. In the other set $\mathrm{HCHO}$ was generated in-situ by the ethene + ozone reaction. The time profiles of $\mathrm{HCHO}$ at SAPHIR were modelled taking into account the chamber properties in both sets and the chemical mechanism in the second set of experiments to predict the expected concentration of $\mathrm{HCHO}$.

\section{Experimental}

\subsection{Atmosphere simulation chamber SAPHIR}

The atmosphere simulation chamber SAPHIR is designed for the investigation of chemical systems at atmospheric concentrations and under controlled conditions (e.g. Rohrer et al., 2005; Bossmeyer et al., 2006; Wegener et al., 2007). The chamber consists of double-walled FEP foil (DuPont). The space between the two foils is flushed continuously with high purity $\mathrm{N}_{2}$. The inner part of the chamber is kept at 40 to $60 \mathrm{~Pa}$ above ambient pressure in order to prevent the contamination with outside air. The chamber is of cylindrical shape (diameter: $5 \mathrm{~m}$, length: $18 \mathrm{~m}$, volume: $270 \mathrm{~m}^{3}$ ) and operated with synthetic air $\left(\mathrm{N}_{2}, \mathrm{O}_{2}\right.$, purity $\left.>99.9999 \%\right)$. A flow controller regulates the replenishment of chamber air lost due to sampling air probes and wall leakage at rates of 6 to $8 \mathrm{~m}^{3} \mathrm{~h}^{-1}$ diluting every trace gas by 2 to $3 \% \mathrm{~h}^{-1}$. The replenishment flow can be operated at rates up to $500 \mathrm{~m}^{3} \mathrm{~h}^{-1}$ to purge trace gas levels in the chamber below the limit of detection. A shutter system keeps the chamber volume in darkness if required, but can also be opened for daylight exposure. All experiments described here were performed in the dark.

The chamber set-up comprises standard instruments for temperature, pressure, humidity, and gas replenishment flow. $\mathrm{O}_{3}$ is measured by an instrument based on absolute UV absorption at $254 \mathrm{~nm}$ (Ansyco). Hydrocarbons are detected by a gas chromatograph (Chrompack) which is described in detail by Wegener et al. (2007). The system is equipped with a flame ionisation detector (FID). Due to sampling (20 min) and sample processing $(30 \mathrm{~min})$ the repetition rate is one data point per $50 \mathrm{~min}$. The system is calibrated on a commercially available certified standard mixture of 30 VOC compounds in synthetic air (NPL). The accuracy of the calibration is better than $8 \%$.

\subsection{High-resolution DOAS Instrument}

The HR-DOAS instrument has been described in detail before (Hausmann et al., 1997; Schlosser et al., 2006), therefore, only a brief summary is given here. The instrument is designed to detect $\mathrm{OH}$ radicals by a number of absorption lines at $308.00 \mathrm{~nm}$ and $308.16 \mathrm{~nm}$. A long path is required to obtain sufficient signal to noise ratio as the ambient daytime concentration of $\mathrm{OH}$ is extremely low, usually 
below $10 \times 10^{6} \mathrm{~cm}^{-3}$. This is achieved by use of a multiplereflection cell (MRC) of $20 \mathrm{~m}$ base with 112 travels corresponding to $2240 \mathrm{~m}$ light path length. A ps-laser is used as a light source emitting broad-band UV-light with a full width at half maximum of $0.42 \mathrm{~nm}$ around $308.1 \mathrm{~nm}$. The power of the UV laser beam is about $1 \mathrm{~mW}$. The light leaving the MRC is transferred to the high resolution spectrograph (SOPRA F1500, $\Delta \lambda=2.7 \mathrm{pm}$ ) and the spectrum is detected by a cooled $\left(-45^{\circ} \mathrm{C}\right)$ photo diode array operated by the MFC program (Gomer et al., 1995). The digitized laser spectrum range of 1024 pixel corresponds to $0.25 \mathrm{~nm}$. The Multichannel Scanning Technique (MCST) is used to reach the required signal to noise ratio (Brauers et al., 1995). One air spectrum is recorded within $135 \mathrm{~s}$. A comparison of measured and modelled MCST spectra is given by Hausmann et al. (1997) who found a maximum $1.7 \%$ error contribution to the accuracy of the measurement. The deconvolution of the measured spectrum is performed by fitting a trigonometric background consisting of 16 terms and three reference spectra, namely $\mathrm{OH}$, $\mathrm{HCHO}$, and an so far unidentified absorber X (Schlosser et al., 2006). We present the HCHO data in units of the optical density (absorbance) at $308.1034 \mathrm{~nm}$ (see Fig. 1, lower panel).

\subsection{Broad-band DOAS instrument}

The setup of the BB-DOAS instrument is described in detail in the thesis of Bossmeyer (2006). It is constructed and installed at the chamber alongside the HR-DOAS instrument for the detection of a large number of species (e.g. HONO, $\mathrm{NO}_{2}, \mathrm{NO}_{3}, \mathrm{O}_{3}$, and $\mathrm{HCHO}$ ). It uses a Xenon arc lamp (Osram $\mathrm{XBO} 75 \mathrm{~W}$ ) as light source and a modified version of a multiple reflection cell that allows 48 travels along the axis of the chamber's cylindrical volume, corresponding to $960 \mathrm{~m}$ light path length. The outgoing light is guided via transfer optics into a Czerny-Turner type spectrograph (Jobin-Yvon, HR460) equipped with a blazed holographic grating offering a spectral resolution of $0.2 \mathrm{~nm}$. A photo diode array (PDA, Hamamatsu, S3904) with 1024 pixels detects a wavelength range of $44 \mathrm{~nm}$. Spectra are acquired through a controller (Hoffmann Messtechnik) at a rate of $1 \mathrm{~min}^{-1}$. The spectra recording, handling and fitting is operated using a script mode of the software DOASIS (Kraus and Geyer, 2001). The HCHO cross section of Meller and Moortgat (2000) at $298 \mathrm{~K}$ is used for the evaluation (Fig. 1, upper panel). The 1- $\sigma$ precision of the BB-DOAS HCHO measurement is approximately $0.5 \mathrm{ppbV}$.

\subsection{Experiment description}

In two experiments $\mathrm{HCHO}$ was generated by thermolysis of para-formaldehyde. A weighted amount of solid paraformaldehyde was heated until it was thermolysed at $383 \mathrm{~K}$ completely into a stream of high purity $\mathrm{N}_{2}(>99.999 \%)$, which flushed the gaseous $\mathrm{HCHO}$ into the chamber. In the first experiments in 2004 a homogeneous mixing ratio level in the chamber was reached after a characteristic dark mixing time of $30 \mathrm{~min}$. In 2005 a fan was operated, which distributed the injection in the chamber within 2 min.

In two experiments the $\mathrm{HCHO}$ was generated in-situ from the gas-phase reaction of $\mathrm{C}_{2} \mathrm{H}_{4}+\mathrm{O}_{3}$. The experiments were conducted in the well purged chamber at $\mathrm{H}_{2} \mathrm{O}$ levels of less than $10 \mathrm{ppmV}$. Fan operation in the chamber during the injection periods guaranteed that the reactants were well mixed within minutes. In the first ethene-ozone experiment $\mathrm{C}_{2} \mathrm{H}_{4}$ and $\mathrm{C}_{3} \mathrm{H}_{8}$ (purities $>99.95 \%$ each) were injected. $\mathrm{C}_{3} \mathrm{H}_{8}$ was used as an inert tracer to monitor the dilution of chamber air independently from the flow controllers. $\mathrm{C}_{2} \mathrm{H}_{4}$ degradation was initiated by the addition of $\mathrm{O}_{3}$. In the second experiment additional $500 \mathrm{ppmV} \mathrm{CO}$ was injected in order to suppress possible reactions of ethene with $\mathrm{OH}$ radicals formed during ozonolysis. During this experiment $\mathrm{C}_{2} \mathrm{H}_{4}$ was added to the chamber again $2 \mathrm{~h}$ after the start of the experiment to enhance $\mathrm{HCHO}$ production.

\section{Results and discussion}

\subsection{Thermolysis experiments}

The profiles of the two days with $\mathrm{HCHO}$ injected into the clean chamber are presented in Fig. 2. Both experiments were performed in a similar way. After measuring at a small dilution rate of about $3 \% / \mathrm{h}$ we increased the replenishment flow in order to clearly reduce the $\mathrm{HCHO}$ concentration by $30 \%$ within $30 \mathrm{~min}$. The range of $\mathrm{HCHO}$ mixing ratios in these chamber experiments was from 0 to $\approx 30 \mathrm{ppbV}$.

The only loss process of $\mathrm{HCHO}$ added to the dark chamber is the dilution by clean synthetic air. Therefore, the concentration $C$ as function of time can be written as

$C(t)=C(0) \times \exp \left(-\int_{0}^{t} k_{\mathrm{Dil}}\left(t^{\prime}\right) d t^{\prime}\right)$

The dilution rate $k_{\mathrm{Dil}}(t)=F(t) / V$ is calculated from the measured replenishment flow $F(t)$ and the chamber volume $V$. The concentrations were calculated in steps of $60 \mathrm{~s}$. The center of the injection period, typically $20 \mathrm{~min}$, was used as injection time for the calculated values to generate comparable data sets. The initial mixing ratio $C_{0}$ was deduced from the weighted para-formaldehyde (Merck, purity $>95 \%$ ) assuming a $100 \%$ conversion to the gas-phase.

Figure 3 presents the scatter plot of the $\mathrm{HCHO}$ mixing ratios measured by the BB-DOAS instrument and the calculated HCHO (Eq. 1). Data points close to the injection of $\mathrm{HCHO}$ were excluded. The whole dataset of $\mathrm{N}=1152$ clearly separates into two groups belonging to the two different days. Both groups highly correlate, however, the regression parameters are different (Table 1). A weighted regression yields small offsets of different sign and slopes of 1.01 and 1.06, respectively. Since only a minority of the data in both cases 

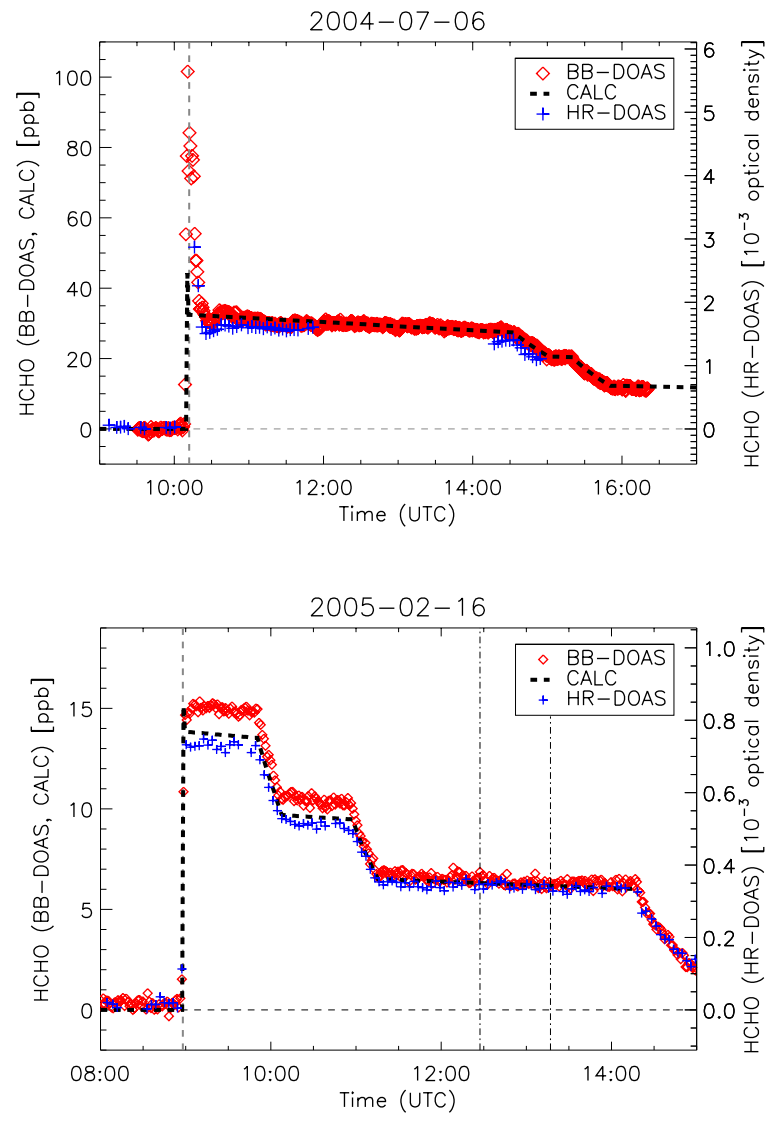

Fig. 2. HCHO profiles of the thermolysis experiments measured by BB-DOAS and HR-DOAS, and the calculated values. Grey vertical line: HCHO injection. Top: 6 July: Since the fan was not operated during injection of $\mathrm{HCHO}$ concentration fluctuations were observed at the start of the experiment. The data from 10:05 to 11:00 were excluded from the correlation (Fig. 3). Bottom: 16 February: The vertical lines (-.-.) after 12:00 mark the two injections of ozone (60 ppbV each) as a check for interferences with the measurements.

is at zero $\mathrm{HCHO}$ mixing ratios a regression through the origin was also included in the analysis. The difference of the slopes is even larger (Fig. 3, Table 1). The accuracy of the $\mathrm{HCHO}$ injection by thermolysis is about $6 \%$ which is in the order of the difference observed here. However, the data of experiment in February $(\mathrm{T}=275 \mathrm{~K})$ show an approximately $5 \%$ to $8 \%$ steeper slope than the summer data $(\mathrm{T}=295 \mathrm{~K})$. This may be explained by a temperature dependence of the $\mathrm{HCHO}$ absorption cross section. According to the data of Meller and Moortgat (2000) an increase by $1 \%$ is expected whereas applying the temperature dependence reported by Cantrell (1990) a change of 7\% is predicted which is closer to our observation. However, the temperature range of the experiments here is not sufficient to deduce a new value for the temperature coefficient.

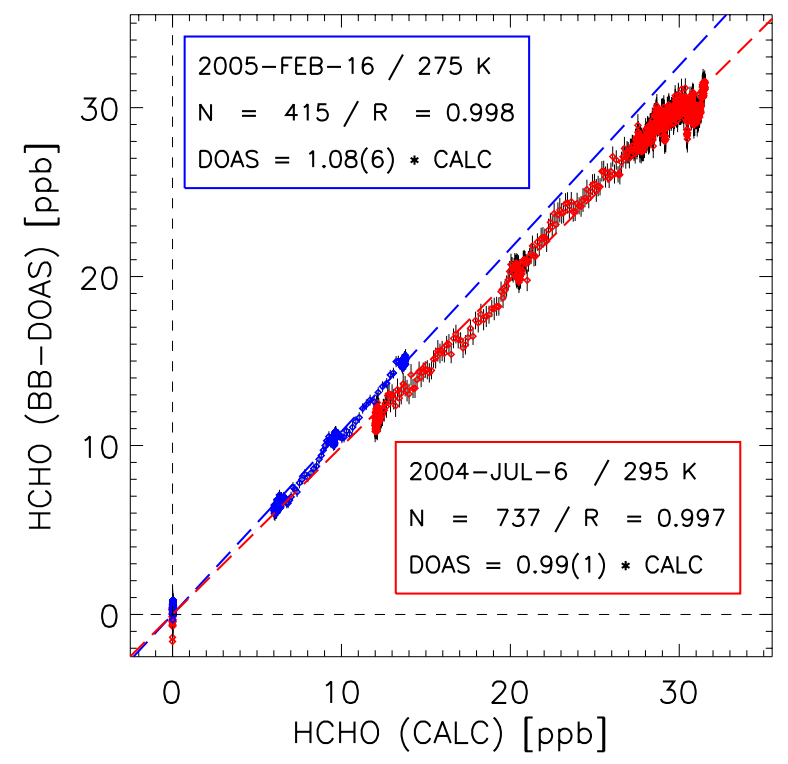

Fig. 3. Correlation of BB-DOAS data with calculated concentrations in the thermolysis experiments. Different colors denote the two different experiments (see Fig. 2). The lines indicate the regression forced through the origin for the respective dataset.

Table 1. Coefficients of correlation and regression of the thermolysis experiments. $N$ : number of data points. $r$ : correlation coefficient. $b_{0}$ : slope of regression forced through the origin $\left(y=b_{0} \times x\right)$. $a, b$ : intercept and slope of weighted linear regression $(y=a+b \times x)$. The numbers in parentheses denote the $1-\sigma$ error of the last digit.

\begin{tabular}{cccccc}
\hline date & $N$ & $r$ & $b_{0}$ & $a[\mathrm{ppb}]$ & $b$ \\
\hline 6 July 2004 & 737 & 0.998 & $1.08(6)$ & $-0.39(9)$ & $1.009(3)$ \\
16 Feb 2005 & 415 & 0.997 & $0.99(1)$ & $+0.13(3)$ & $1.055(4)$ \\
\hline
\end{tabular}

\subsection{Ozonolysis experiments}

The homogeneous production of $\mathrm{HCHO}$ from the ozonolysis of ethene provides an alternative way to compare $\mathrm{HCHO}$ measurements in the chamber. The reaction is well known because it represents the simplest alkene + ozone reaction which is an important oxidation pathway for atmospheric VOC. The monitored loss of ethene and ozone in combination with the accurate knowledge of the involved reactions and their rate constants allows to model the yield of $\mathrm{HCHO}$ and to compare the predicted concentration with the measurements. As shown in Table 2, HCHO is the primary product of the ozonolysis (Reaction R1). However, reactions of the formed stabilised Criegee intermediate $\left(\mathrm{CH}_{2} \mathrm{OO}\right)$ with $\mathrm{H}_{2} \mathrm{O}$ (Reaction R3b) or CO (Reaction R4) will yield additional HCHO. The degradation of ethene is also initiated by hydroxy radicals leading to the formation of $\mathrm{HCHO}$ via 
Table 2. The ozone + ethene reaction and the production of $\mathrm{HCHO}$.

\begin{tabular}{llll}
\hline (R1) & $\mathrm{C}_{2} \mathrm{H}_{4}+\mathrm{O}_{3}$ & $\longrightarrow$ & $\mathrm{CH}_{2} \mathrm{OO}+\mathbf{H C H O}$ \\
(R2a) & $\mathrm{CH}_{2} \mathrm{OO}^{*}+\mathrm{M}$ & $\longrightarrow$ & $\mathrm{CO}+\mathrm{H}_{2} \mathrm{O}+\mathrm{M}$ \\
(R2b) & $\mathrm{CH}_{2} \mathrm{OO}^{*}+\mathrm{O}_{2}$ & $\longrightarrow$ & $\mathrm{CO}+\mathrm{OH}+\mathrm{HO}_{2}$ \\
(R2c) & $\mathrm{CH}_{2} \mathrm{OO}^{*}+\mathrm{M}$ & $\longrightarrow$ & $\mathrm{CH}_{2} \mathrm{OO}+\mathrm{M}$ \\
(R3a) & $\mathrm{CH}_{2} \mathrm{OO}+\mathrm{H}_{2} \mathrm{O}$ & $\longrightarrow$ & $\mathrm{HCOOH}+\mathrm{H}_{2} \mathrm{O}$ \\
(R3b) & $\mathrm{CH}_{2} \mathrm{OO}+\mathrm{H}_{2} \mathrm{O}$ & $\longrightarrow$ & $\mathbf{H C H O}+\mathrm{H}_{2} \mathrm{O}_{2}$ \\
(R4) & $\mathrm{CH}_{2} \mathrm{OO}+\mathrm{CO}$ & $\longrightarrow$ & $\mathbf{H C H O}+\mathrm{CO}_{2}$ \\
\hline
\end{tabular}

secondary pathways. The $\mathrm{HCHO}+\mathrm{OH}$ reaction is a sink of the product. Even in the dark chamber, there is a significant yield of $\mathrm{OH}$ via the reaction of the energy rich Criegee intermediate and molecular oxygen (Reaction R2b). To model the $\mathrm{HCHO}$ formation in the chamber we used the master chemical mechanism MCM (Saunders et al., 2003) in its current version 3.1, where we also included the dilution of all compounds by the replenishment flow. The MCM is the reference mechanism for the gas phase reaction of atmospheric species.

Therefore, two different ozonolysis experiments in the dark chamber were planned to investigate the $\mathrm{HCHO}$ yield: During the first experiment (15 February 2005) ethene is consumed both by the added ozone and the produced $\mathrm{OH}$. For the second experiment (17 February 2005) an excess of $500 \mathrm{ppmV}$ of $\mathrm{CO}$ was added to scavenge the $\mathrm{OH}$ radicals in order to reduce the number of reactions important to the production or loss of HCHO. Boundary conditions of the detailed model are the measured time profiles of ethene, ozone, humidity, temperature, pressure, and dilution of all species by the replenishment flow. Since the $\mathrm{OH}$ concentration was expected to be well below the detection limit of the HRDOAS instrument in both experiments, the $\mathrm{OH}$ concentration was used as a free parameter and predicted by the model. In a second model run the HCHO yield was used as a free parameter and the BB-DOAS measurement of $\mathrm{HCHO}$ were used as a constraint instead.

The results of the measurements and the model calculations are presented in Fig. 4. For the first experiment the MCM predicts a $\mathrm{HCHO}$ yield of 1.00 while $0.91 \pm 0.29$ is found by the fit to the whole data set of BB-DOAS measurements. However, if we restricted the fit to the first $6 \mathrm{~h}$ of the experiment the experimental yield would even more closely match the MCM calculation. For the second, high $\mathrm{CO}$, experiment both the model and the measurement find a higher $\mathrm{HCHO}$ yield. This can be attributed to the very high $\mathrm{CO}$ concentration that was used to scavenge $\mathrm{OH}$ at low humidity. There is no loss of $\mathrm{HCHO}$ through $\mathrm{OH}$, but the reaction of the stabilized Criegee intermediate $\left(\mathrm{CH}_{2} \mathrm{OO}\right)$ with $\mathrm{CO}$ (Reaction R4) becomes important leading to an increase of the HCHO yield. However, a significant difference between the HCHO yield predicted by the MCM (1.37) and the BB-DOAS measurement $(1.08 \pm 0.19)$ is observed. The
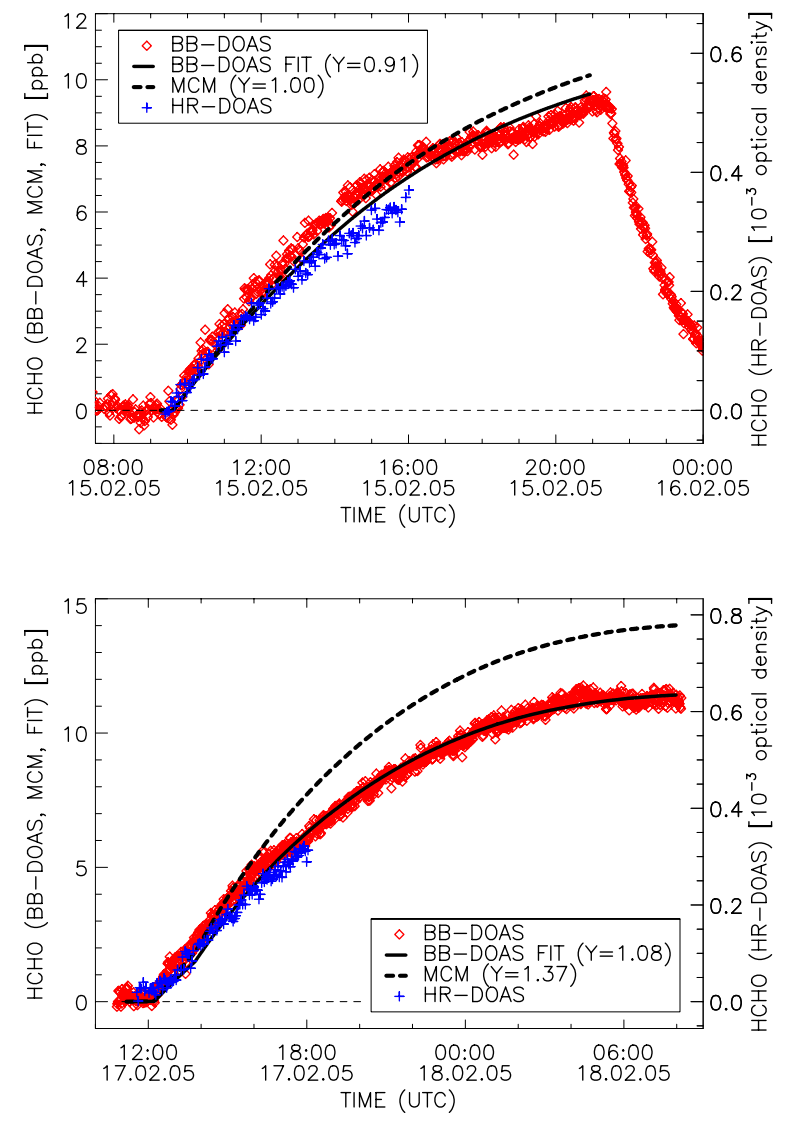

Fig. 4. HCHO time profiles in the ethene-ozone experiments performed in February 2005 (top: low CO; bottom: high CO). Dotted line: best fit of modelled $\mathrm{HCHO}$ data to the measurement of the BB-DOAS (hollow diamonds) applying the yield based on $\mathrm{C}_{2} \mathrm{H}_{4}$ consumption as fit parameter. Dashed line: yield predicted by the MCM. Agreement between the BB-DOAS measurement and the MCM model is found for 15 February 2007, whereas in the experiment of 15 February 2007 the model overestimates the HCHO yield. The HR-DOAS measurement (red) is also shown, but in units of the optical density (right axis). It can be compared on a relative scale.

good agreement of the thermolysis experiments and the low $\mathrm{CO}$ experiment suggests an error in the model. Only two reactions leading to the production of $\mathrm{HCHO}$ may be responsible since $\mathrm{OH}$ is scavenged. Either the stabilization yield of the excited Criegee (Reaction R2c) is significantly lower than presumed or the reaction of the stabilized Criegee with $\mathrm{CO}$ (Reaction R4) is much slower. We assume the latter case since the yields of Reactions (R2a), (R2b), and (R2c) are well known. Reaction (R4) is not well investigated. In order to fit our observations we had to divide the rate constant by a factor $\beta$ of $250\left(k_{4}=5 \times 10^{-18} \mathrm{~cm}^{3} \mathrm{~s}^{-1}\right)$. Since the sensitivity of this experiment to the rate is small, a range of 100 to 500 for $\beta$ is compatible with a $\pm 3 \%$ calibration error of the $\mathrm{HCHO}$ measurement. Therefore, an independent determination of this rate constant would be useful. 


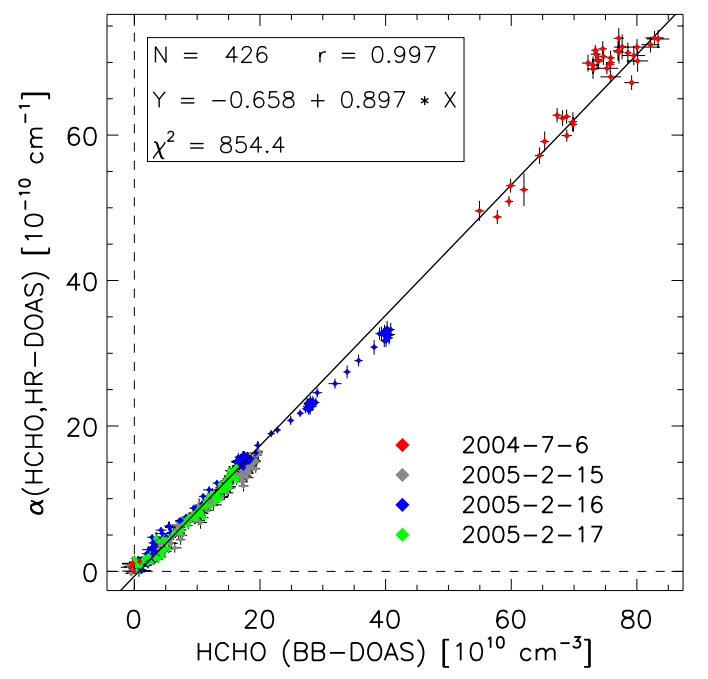

Fig. 5. Correlation of all simultaneously measured HR-DOAS and BB-DOAS data. The data were recorded during 2 thermolysis and 2 ozonolysis experiments. We fitted a line with errors in both coordinates. The slope (in units of $10^{-20} \mathrm{~cm}^{2}$ ) corrsponds to the differential absorption cross section of a line at $308.1034 \mathrm{~nm}$ (marked in Fig. 1). The differential absorption coefficient $\alpha=\sigma^{\prime} \times[\mathrm{HCHO}]$ was calculated from the measured differential optical density divided by path length $(2240 \mathrm{~m})$.

\subsection{High resolution $\mathrm{HCHO}$ cross section at $308 \mathrm{~nm}$}

Simultaneous DOAS measurements of both the BB-DOAS instrument and the HR-DOAS instrument were recorded for all experiments (Figs. 2 and 4). BB-DOAS measurements that are linked to absorption cross section measurements (Meller and Moortgat, 2000) can be used to determine the unknown highly resolved differential absorption cross section $\left(\sigma^{\prime}\right)$ needed for the HR-DOAS instrument (Fig. 5). Several concentration values measured by the BB-DOAS instrument were averaged if they occurred within one HR-DOAS interval. An excellent correlation coefficient $\mathrm{r}=0.997$ was found for the two data sets. The slope of the linear regression is used to calculate $\sigma^{\prime}$ of a HCHO absorption line line at $308.1034 \mathrm{~nm}$ as a reference using the high resolution of the HR-DOAS $(\Delta \lambda=2.7 \mathrm{pm})$. A value of $6.08 \times 10^{-21} \mathrm{~cm}^{2}$ for the same line was reported earlier by (Neuroth, 1991; Brandenburger et al., 1998) who also used a BB-DOAS instrument for calibration, but it was based on a different absorption cross section (Platt et al., 1979) and they had a lower resolution. Including the down-scaling effect (factor $=0.729$ ) of the MCST detection method we found an effective differential absorption cross section for the HCHO absorption line marked in Fig. 1 of $\sigma^{\prime}=8.97 \times 10^{-21} \mathrm{~cm}^{2}$ with an accuracy of $6 \%$ accounting for the uncertainty of the dilution and the purity of para-formaldehyde.

The recent publication of Smith et al. (2006) provides a $\mathrm{HCHO}$ spectrum at a resolution $(3.5 \mathrm{pm})$ which is close
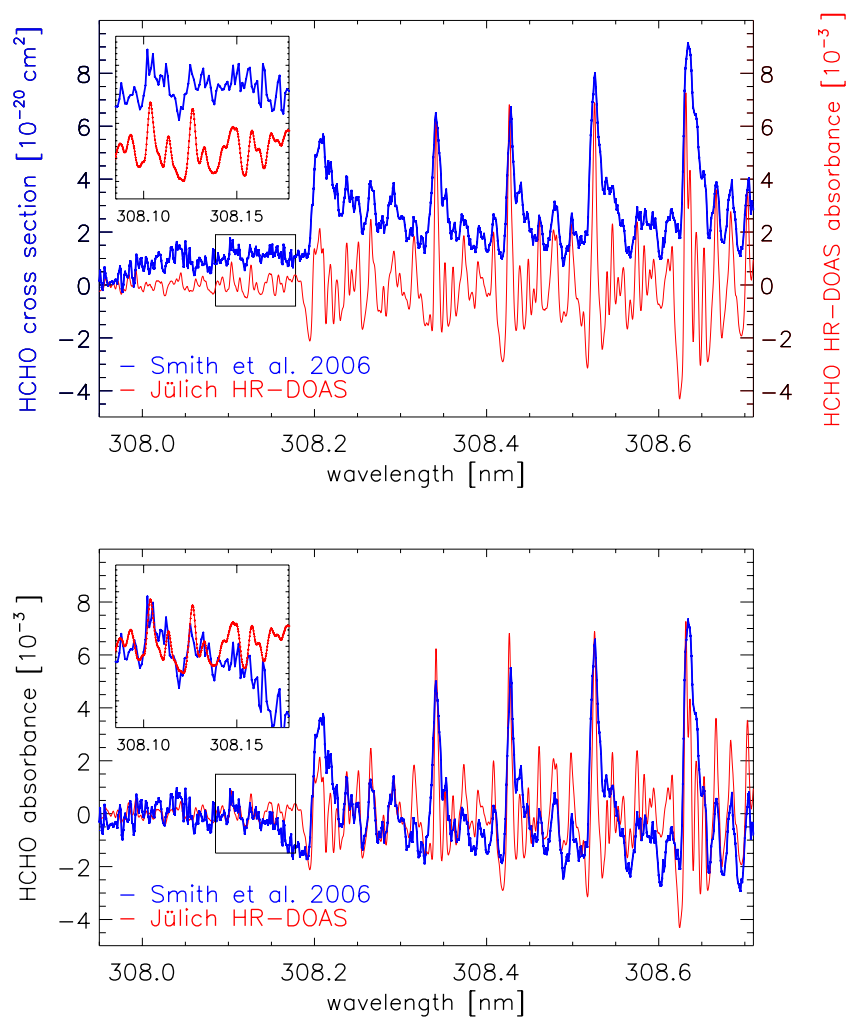

Fig. 6. Comparison of the HCHO absorption cross section of Smith et al. (2006) and the HR-DOAS absorbance. The extended spectral range of the HR-DOAS was recorded in 7 overlapping frames of $0.21 \mathrm{~nm}$ each. The insets expand the spectral range which contains the main HCHO features recorded by the HR-DOAS instrument when used for $\mathrm{OH}$ measurements. The upper frame shows the original Smith et al. (2006) data (left axis, blue) and the highpass filtered HR-DOAS spectrum (right axis, red). In the lower frame we multiplied the Smith et al. cross-sections with the light path $(2240 \mathrm{~m})$ and $\mathrm{HCHO}$ concentration $\left(5.7 \times 10^{11} \mathrm{~cm}^{-3}\right.$, mixing ratio $23 \mathrm{ppb}$ ) which were present during the experiment when we recorded all HR-DOAS spectra of this figure. We also applied the same high-pass filter which we used for HR-DOAS data.

to that of our HR-DOAS instrument $(2.7 \mathrm{pm})$. This spectrum could, in principle, provide an independent way of calibrating the HR-DOAS instrument. We compared the absorbance recorded over an extended wavelength range of $0.75 \mathrm{~nm}$ (Fig. 6). For the major absorption features both instruments show clearly the same line positions and relative line strengths. However, the weaker lines in the HR-DOAS spectrum are not reproduced by the Smith et al. (2006) data (e.g. see inset of Fig. 6). All features seen in the HR-DOAS spectrum are well above the detection limit of $5 \times 10^{-5}$. We assume that also the stronger absorption lines might be influenced by the effect observed at the weaker lines. Therefore, we refrained from using Smith et al. (2006) data for the calibration of our instrument. 


\section{Conclusions}

We performed 4 experiments on formaldehyde in the SAPHIR chamber. The experiments were designed to improve the knowledge on the absorption cross sections used for DOAS in the atmosphere.

In the two thermolysis experiments $\mathrm{HCHO}$ concentrations were calculated from the sample weight of paraformaldehyde and the gas replenishment flows at the chamber. The calculated concentrations are qualitatively and quantitatively reproduced by the BB-DOAS evaluation using the current absorption cross section recommendation (Meller and Moortgat, 2000). When other literature cross sections were used deviations of up to $20 \%$ from the good agreement would appear. Since the experiments were performed at different temperatures $(\Delta T=20 \mathrm{~K})$ the Cantrell (1990) temperature dependence is supported. Since the cross section changes significantly over the temperature range observed in the atmosphere, the temperature dependence of the $\mathrm{HCHO}$ absorption cross section remains an important issue to be resolved.

In this study we present an approach to calibrate the differential optical density of $\mathrm{HCHO}$ at a resolution of $2.7 \mathrm{pm}$ between $307.97 \mathrm{~nm}$ and $308.18 \mathrm{~nm}$. This is an important step to make use of the HCHO data simultaneously measured with $\mathrm{OH}$ by a DOAS instrument.

Finally, an ethene-ozone experiment conducted under high $\mathrm{CO}$ conditions showed that measured $\mathrm{HCHO}$ yields underestimated predictions of the MCM 3.1. The most likely explanation is an overestimation of the rate coefficient of the $\mathrm{CH}_{2} \mathrm{OO}+\mathrm{CO}$ reaction in the MCM. This is of minor effect in the atmosphere since the ratio of $\mathrm{CO} / \mathrm{H}_{2} \mathrm{O}$ normally promotes the $\mathrm{CH}_{2} \mathrm{OO}+\mathrm{H}_{2} \mathrm{O}$ reaction. However, this finding is important for experiments at low humidities and high $\mathrm{CO}$ levels in chamber experiments. Therefore, a re-determination of this rate and similar reactions would be worthwhile.

Acknowledgements. This work was supported by the EU FP-6 program EUROCHAMP. We thank U. Platt (U. Heidelberg) and B. Bohn for helpful discussions, R. Häseler and F. J. Johnen for assistance with the experiments, and T. Langner and $\mathrm{H}$. Schütze (Foiltec, Bremen) for engineering work when setting up the SAPHIR chamber.

Edited by: M. Ammann

\section{References}

Atkinson, R., Baulch, D. L., Cox, R. A., Crowley, J. N., Hampson, R. F., Hynes, R. G., Jenkin, M. E.,Rossi, M. J., and Troe, J.: Evaluated kinetic and photochemical data for atmospheric chemistry: Volume II reactions of organic species, Atmos. Chem. Phys., 6, 3625-4055, 2006,

http://www.atmos-chem-phys.net/6/3625/2006/.

Bass, A. M., Glasgow, L. C., Miller, C., Jesson, J. P., and Filkin, D. L.: Temperature dependent absorption cross sections for formaldehyde $\left(\mathrm{CH}_{2} \mathrm{O}\right)$ : The effect of formaldehyde on stratospheric chlorine chemistry, Planet. Space Sci., 28, 675-679, 1980.

Bogumil, K., Orphal, J., Homann, T., Voigt, S., Spietz, P., Fleischmann, O. C., Vogel, A., Hartmann, M., Bovensmann, H., Frerick, J., and Burrows, J. P.: Measurements of molecular absorption spectra with the SCIAMACHY pre-flight model: Instrument characterization and reference data for atmospheric remote sensing in the 230-2380 $\mathrm{nm}$ region, J. Photochem. Photobiol. A, 157, 167-184, 2003.

Bossmeyer, J.: Studies of Aldehydes in an Atmosphere Simulation Chamber, PhD thesis, Universität Heidelberg, Germany, 2006.

Bossmeyer, J., Brauers, T., Richter, C., Rohrer, F., Wegener, R., and Wahner, A.: Simulation Chamber Studies on the $\mathrm{NO}_{3}$ Chemistry of Atmospheric Aldehydes, Geophys. Res. Lett., 33(18), L18810, doi:10.1029/2006GL026778, 2006.

Brandenburger, U., Brauers, T., Dorn, H.-P., Hausmann, M., and Ehhalt, D. H.: In-situ measurement of tropospheric hydroxyl radicals by folded long-path laser absorption during the field campaign POPCORN in 1994, J. Atmos. Chem., 31, 181-204, 1998.

Brauers, T., Hausmann, M., Brandenburger, U., and Dorn, H.-P.: Improvement of Differential Optical Absorption Spectroscopy with a multichannel scanning technique, Appl. Opt., 34, 44724479, 1995.

Brauers, T., Hausmann, M., Bister, A., Kraus, A., and Dorn, H.-P.: $\mathrm{OH}$ radicals in the boundary layer of the Atlantic Ocean 1. Measurements by long-path laser absorption spectroscopy, J. Geophys. Res., 106, 7399-7414, 2001.

Cantrell, C. A., Davidson, J. A., McDaniel, A. H., Shetter, R. E., and Calvert, J. G.: Temperature-dependent formaldehyde cross sections in the near-ultraviolet spectral region, J. Phys. Chem., 94, 3902-3908, 1990.

Carlier, P., Hannachi, H., and Mouvier, G.: The Chemistry of Carbonyl Compounds in the Atmosphere - a review, Atmos. Environ., 20, 2079-2099, 1986.

De Haan, D. O., Brauers, T., Oum, K., Stutz, J., Nordmeyer, T., and Finlayson-Pitts, B.J.: Heterogeneous chemistry in the troposphere: experimental approaches and applications to the chemistry of sea salt particles, Int. Rev. Phys. Chem., 18(3), 343-385, 1999.

Finlayson-Pitts, B. J. and Pitts, J. N.: Chemistry of the Upper and Lower Atmosphere - Theory, Experiments and Applications, Academic Press, San Diego, 2000.

Gomer, T., Brauers, T., Heintz, F., Stutz, J., and Platt, U.: MFC User Manual, Version 1.98, Institut für Umweltphysik, Universität Heidelberg, 1995.

Gratien, A., Picquet-Varrault, B., Orphal, J., Perraudin, E., Doussin, J.-F., and Flaud, J.-M.: Laboratory intercomparison of the formaldehyde absorption cross sections in the infrared (1660$\left.1820 \mathrm{~cm}^{-1}\right)$ and ultraviolet $(300-360 \mathrm{~nm})$ spectral regions, J. Geophys. Res., 112, D05305, doi:10.1029/2006JD007201, 2007.

Hak, C., Pundt, I., Trick, S., et al.: Intercomparison of four different in-situ techniques for ambient formaldehyde measurements in urban air, Atmos. Chem. Phys., 5, 2881-2900, 2005, http://www.atmos-chem-phys.net/5/2881/2005/.

Hausmann, M., Brandenburger, U., Brauers, T., and Dorn, H.-P.: Detection of tropospheric $\mathrm{OH}$ radicals by long-path differentialoptical-absorption spectroscopy: Experimental setup, accuracy, and precision, J. Geophys. Res. 102, 16011-16 022, 1997. 
Kleffmann, J., Lörzer, J. C., Wiesen, P. Kern, C., Trick, S., Volkamer, R., Rodenas, M., and Wirtz, K.: Intercomparison of the DOAS and LOPAP techniques for the detection of nitrous acid (HONO), Atmos. Environ., 40, 3640-3652, 2006.

Kraus, S. and Geyer, A.: DOASIS Jscript programming description, Institut für Umweltphysik, University of Heidelberg, 2001.

Meller, R. and Moortgat, G. K.: Temperature dependence of the absorption cross sections of formaldehyde between 223 and $323 \mathrm{~K}$ in the wavelength range $225-375 \mathrm{~nm}$, J. Geophys. Res., 201(D6), 7089-7101, 2000.

Neuroth, R., Dorn, H.-P., and Platt, U.: High resolution spectral features of a series of aromatic hydrocarbons and $\mathrm{BrO}$ : Potential interferences in the atmospheric $\mathrm{OH}$-measurements, J. Atmos. Chem., 12, 287-298, 1991.

Platt, U.: Differential Optical Absorption Spectroscopy, Air Monitoring by, In: R. A. Meyers (Ed.), Encyclopedia of Analytical Chemistry, John Wiley \& Sons Ltd (Chichester), 1936, 2000.

Platt, U., Perner, D., and Pätz, H. W.: Simulataneous measurements of atmospheric $\mathrm{CH}_{2} \mathrm{O}, \mathrm{O}_{3}$, and $\mathrm{NO}_{2}$ by differential optical absorption, J. Geophys. Res, 84, 6329-6335, 1979.

Pope, F. D., Smith, C. A., Ashfold, M. N. R., and Orr-Ewing, J.: High-resolution absorption cross sections of formaldehyde at wavelengths from 313 to $320 \mathrm{~nm}$, Phys. Chem. Chem. Phys., 7, 79-84, 2005.

Rogers, J. D.: Ultraviolet absorption cross sections and atmospheric photodissociation rate constants of formaldehyde, J. Phys. Chem., 94, 4011-4015, 1990.

Rohrer, F., Bohn, B., Brauers, T., Brüning, D., Johnen, F.-J., Wahner, A., and Kleffmann, J.: Characterisation of the photolytic HONO-source in the atmosphere simulation chamber SAPHIR, Atmos. Chem. Phys., 5, 2189-2201, 2005, http://www.atmos-chem-phys.net/5/2189/2005/.
Sander, S. P., Finlayson-Pitts, B. J., Friedl, R. R., et al.: Chemical Kinetics and Photochemical Data for Use in Atmospheric Studies, NASA Panel for Data Evaluation Number 15, JPL Publication 06-2, Pasadena, 2006.

Saunders, S. M., Jenkin, M. E., Derwent, R. G., and Pilling, M. J.: Protocol for the development of the Master Chemical Mechanism, MCM v3 (Part A): tropospheric degradation of nonaromatic volatile organic compounds, Atmos. Chem. Phys., 3, 161-180, 2003, http://www.atmos-chem-phys.net/3/161/2003/.

Schlosser, E., Bohn, B., Brauers, T., Dorn, H.-P., Fuchs, H., Häseler, R., Hofzumahaus, A., Holland, F., Rohrer, F., Rupp, L. O., Siese, M., Tillmann, R., and Wahner, A.: Intercomparison of Two Hydroxyl Radical Measurement Techniques at the Atmosphere Simulation Chamber SAPHIR, J. Atmos. Chem., 56(2), 187-205, doi:10.1007/s10874-006-9049-3, 2006.

Smith, C. A., Pope, F. D., Cronin, B., Parkes, C. B., and Orr-Ewing, A. J.: Absorption cross sections of formaldehyde at wavelengths from 300 to $340 \mathrm{~nm}$ at 294 and $245 \mathrm{~K}$, J. Phys. Chem. A, 110, 11 645-11 653, doi:10.1021/jp063713y, 2006.

Su, F., Calvert, J. G., and Shaw, H.: A FTIR Spectroscopic Study of the Ozone-Ethene Reaction Mechanism in $\mathrm{O}_{2}$-Rich Mixtures, J. Phys. Chem., 84(3), 239-246, 1980.

Wegener, R., Brauers, T., Koppmann, R. Rodríguez Bares, S., Rohrer, F., Tillmann, R., Wahner, A., Hansel, A., and Wisthaler, A.: Investigation of the ozonolysis of short chained alkenes in the atmosphere simulation chamber SAPHIR, J. Geophys. Res., 112, D13301, doi:10.1029/2006JD007531, 2007. 